\title{
УДК 621.226
}

\section{B.I. Мандрус}

Академія сухопутних військ імені гетьмана Петра Сагайдачного, Львів

\section{СПОСІБ ПОБУДОВИ ВИХІДНОЇ ХАРАКТЕРИСТИКИ ГІДРОТРАНСФОРМАТОРА ПРИ СПІЛЬНІЙ РОБОТІ 3 ДВИГУНОМ}

Запропонований спрощчений спосіб побудови вихідної характеристики гідротрансформатора при спільній роботі з двигуном, який в порівнянні з існуючим зменшує кількість розрахунків $i$, отже, можливість помилок, щчо виникають при проектуванні і виконанні розрахунково-графічних завдань студентами, курсантами, слухачами.

Ключові слова: гідротрансформатор, характеристики гідротрансформатора, гідромеханічна передача.

\section{Постановка проблеми}

В сучасних автомобілях та інших сухопутних колісних та гусеничних транспортних засобах широко використовуються автоматичні коробки передач, або так звані гідромеханічні передачі (ГМП) [1, $4,5]$. Вони складаються 3 двох основних агрегатів: гідротрансформатора і механічного редуктора.

Однією з основних частин проектування ГМП є розрахунок та побудова характеристик гідротрансформатора при спільній роботі з двигуном. Існуючі способи побудови характеристик $[3,6]$ потребують значної кількості розрахунків, що може призвести до помилок. Особливо часто помилки допускають курсанти, студенти, слухачі при виконанні розрахунково-графічного завдання.

\section{Аналіз досліджень і публікацій}

Гідромеханічні передачі застосовуються в транспортних засобах, які під час експлуатації часто зупиняються i рушають 3 місця під великим вантажем (міські автобуси), переборюють опори руху, що різко змінюються за значенням (кар'єрні самоскиди, великовантажні автомобілі підвищеної прохідності, автонавантажувачі, тягачі, трактори, базові машини бойової техніки), мають підвищені вимоги до комфорту (легкові автомобілі).

Гідромеханічні передачі широко використовуються завдяки своїм перевагам:

1. Плавний запуск машини під навантаженням.

2. Плавна (безступенева) й автоматична зміна швидкості та моменту при зміні зовнішнього опору (при збільшенні опору швидкість машини зменшується, а момент на вихідному валу передачі збільшується).

3. Надійне запобігання двигуна від перевантажень, зменшення динамічних навантажень, які передаються на двигун.

4. Підвищення прохідності транспортних машин на слабких грунтах, нерівних дорогах.

Ці якості ГМП дозволяють збільшити термін служби двигуна і трансмісії на 50...100\%, зменшити потужність двигуна, яка забезпечує рушання 3 місця і розгін машини, суттєво полегшити працю водія.
Для ефективного засвоєння навчального матеріалу i розуміння будови та особливостей роботи ГМП курсантам, студентам і слухачам необхідно навчитися розраховувати вихідну характеристику гідротрансформатора при заданому типу двигуна i виду автомобіля. Це вміння засвоюється під час виконання розрахунковографічного завдання.

Нагадаємо основні параметри та характеристики гідротрансформатора [3, 6]:

Кінематичні - частота обертання вала насоса $n_{1}$, турбіни $n_{2}$, передавальне відношення $i=n_{2} / n_{1}$.

Силові - момент насоса $M_{H}$, турбіни $M_{T}$, коефіцієнт трансформації моменту $K=M_{T} / M_{H}$.

Момент насоса

$$
M_{H}=\frac{\rho \lambda \pi^{2} n_{1}^{2} D^{5}}{900} .
$$

Коефіиієнт моменту насоса

$$
\lambda=\frac{900 M_{H}}{\rho \pi^{2} n_{1}^{2} D^{5}} .
$$

Його значення змінні від $\lambda_{\text {MAX }}$ при $i=0$ до $\lambda=0$ при $i=1$. Сучасний досвід [3, 6] показує, що значення $\lambda_{\mathrm{MAX}}$ доцільно приймати стандартні для вантажних автомобілів $(1,52$ або 1,8 або 2,14$) \cdot 10^{-3}$, для автобусів - $(2,14 ; 2,59 ; 3,02) \cdot 10^{-3}$, для легкових автомобілів $(3,02 ; 4,02 ; 4,82) \cdot 10^{-3}$.

Активний діаметр $D$, тобто найбільший діаметр протічної частини насосного і турбінного коліс

$$
D=\sqrt[5]{\frac{900 \cdot M_{д М А X}}{\lambda_{M A X} \rho \pi^{2} n_{Д}^{2}}} .
$$

Тут $M_{\text {ДмАХ }}$ - максимальний момент на характеристиці двигуна, $n_{д}$ - частота обертання вала

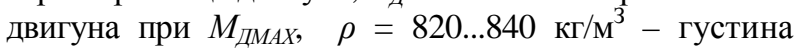
технічної олії для гідропередач.

Навантажувальна характеристика - залежність $M_{H}=f\left(n_{1}, \lambda\right)$.

Характеристика входу при спільній роботі двигуна з гідротрансформатором - графік, на якому 
нанесені швидкісна характеристика двигуна i навантажувальні характеристики при різних значеннях $\lambda$ (рис. 1).

Безрозмірні характеристики - залежності $K=$ $f(i)$ i $\lambda=f(i)$ (рис. 2).

Характеристика виходу при спільній роботі двигуна з гідротрансформатором - залежність $M_{T}=$ $f\left(n_{2}\right)$ (рис. 3).

При проектуванні комплексу двигун - гідромеханічна передача необхідно спочатку вибрати типорозмір гідротрансформатора і побудувати його безрозмірні характеристики згідно 3 параметрами ГОСТ 20228-74, як це показано на рис. 2 [2, 3, 6]. Далі розрахувати і побудувати характеристику входу.

Для її побудови з безрозмірної характеристики гідротрансформатора $\lambda=f(i)$ при деяких значеннях $i$ визначають $\lambda$, i, задаючись кількома значеннями $n_{H}$, за формулою (1) вираховують ряд значень $M_{H}$. Для кожного із значень $i$ точки $з$ координатами $\left[M_{H}, n_{1}\right]$ наносять на графік і з'єднують плавною лінією (рис.1). Режими спільної роботи двигуна i гідротрансформатора визначаютъся точками перетину кривих $M_{д}$ i $M_{H} A, B, C, D$.

Розгляд спільної роботи двигуна з гідротрансформатором закінчується побудовою характеристики виходу. Для цього 3 безрозмірної характеристики гідротрансформатора $K=f(i)$ для кожного значення $i$ визначають $K$. Далі для кожної з точок $A, B, C, D$ розраховують $n_{2}=i \cdot n_{1}$ та $M_{T}=K \cdot M_{H}$. 3 a обчисленими значеннями будують характеристику виходу (рис. 3).

Як показує досвід викладача, розрахунки за наведеною методикою часто супроводжуються ускладненнями, особливо при визначенні характеристики входу: курсантам складно з'ясувати, при яких значеннях $n_{1}$ потрібно розраховувати $M_{H}$, окрім того, при великій кількості підрахунків можливість помилок також велика.

\section{Мета даної роботи}

Розробка спрощеного способу побудови вихідної характеристики гідротрансформатора, який в порівнянні 3 існуючим зменшував би кількість розрахунків i, отже, можливість помилок, що виникають при виконанні розрахунково-графічних завдань студентами, курсантами, слухачами.

\section{Виклад основного матеріалу}

Спрощення розрахунків полягає в тому, що замість розрахунків і побудови характеристики входу на швидкісній характеристиці двигуна $M_{\text {д }}=f\left(n_{2}\right)$ (рис. 1) позначають кілька точок, які є спільними для навантажувальних характеристик гідротрансформатора зі змінними параметрами $\lambda$ : точка $A^{\prime}$ (збігається 3 точкою $A$ ) - точка максимального моменту; точка $D^{\prime}$ (збігається $з$ точкою $D$ ) - крайня права точка характеристики, що відповідає максимальній потужності двигуна; точка $C^{\prime}$ знаходиться посередині або трохи лівіше від середини відрізку $A^{\prime} D^{\prime}$; точка $B^{\prime}-$ на третині відстані $A^{\prime} C^{\prime}$ ближче до точки $A^{\prime}$.

Далі за параметрами точки $A^{\prime}$ за формулою (3) розраховують діаметр, вибирають типорозмір гідротрансформатора і будують його безрозмірні характеристики (рис. 2). Потім для кожної з точок $A^{\prime}, B^{\prime}, C^{\prime}, D^{\prime}$ за формулою (2) розраховують коефіці$\epsilon$ нт моменту насоса $\lambda$, за яким 3 безрозмірних характеристик визначають параметри $i$ та $K$. Надалі для кожної з точок $A^{\prime}, B^{\prime}, C^{\prime}, D^{\prime}$ розраховують $M_{T}=K \cdot M_{H}, n_{2}=i \cdot n_{1}$. За обчисленими значеннями будують харак-теристику виходу, тобто залежність моменту на валу турбіни від частоти його обертання $M_{T}=f\left(n_{2}\right)$ (рис. 3).

Детальне пояснення виконання розрахунків за двома наведеними способами описано в наступному прикладі.

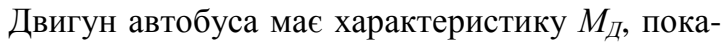
зану на рис. 1. Підібрати типорозмір гідротрансформатора, розрахувати і побудувати вихідну характеристику вибраного гідротрансформатора при спільній роботі з вказаним двигуном.

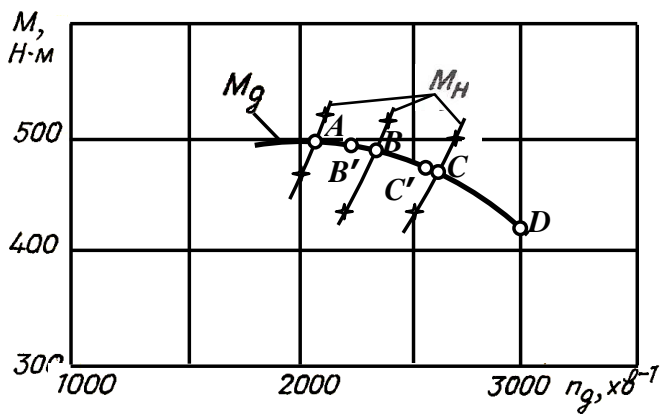

Puc. 1. Характеристики: двигуна $M_{Д}$ i насоса $M_{H}$

Розв'язання. Для автобуса і двигуна з $M_{\text {дмАХ }}=$ $500 \mathrm{H} \cdot$ м приймаємо $\lambda_{\text {MAX }}=2,59 \cdot 10^{-3}$. За формулою (3) розраховуємо активний діаметр гідротрансформатора

$$
\begin{gathered}
D=\sqrt[5]{\frac{900 \cdot M_{\text {Дмах }}}{\lambda_{\text {мах }} \rho \pi^{2} n_{Д}^{2}}}=\sqrt[5]{\frac{900 \cdot 500}{2,59 \cdot 10^{-3} \cdot 840 \cdot 3,14^{2} \cdot 2060^{2}}}= \\
=\sqrt[5]{0,00478}=0,345 \mathrm{M} .
\end{gathered}
$$

Найближчий менший стандартний діаметр $D=340$ мм. Вибираємо триколісний гідротрансформатор, його шифр Г3-340-36 і безрозмірні параметри $\lambda_{M A X}=2,59 \cdot 10^{-3}, \lambda_{P}=1,83 \cdot 10^{-3}$ (при $K=1$ ), $K_{0}=2,6$ (при $\left.i=0\right), K_{80}=1,7$ (при ККД $=80 \%$ ) відповідно до ГОСТ 20228-74 [2]. Будуємо безрозмірні характеристики вибраного гідротрансформатора (рис. 2).

Спочатку наносимо точку $K_{0}=2,6$. Для визначення положення точки $K_{80}$ підрахуємо $i=\eta / K_{80}=$ $0,8 / 1,7=0,47$. Через дві точки проводимо пряму лінію $K$. Наносимо точки $\lambda_{M A X}=2,59 \cdot 10^{-3}$ при $i=0$, $\lambda_{P}=1,83 \cdot 10^{-3}$ при $K=1, \lambda=0$ при $i=1$ і з'єднуємо їх плавною лінією. 


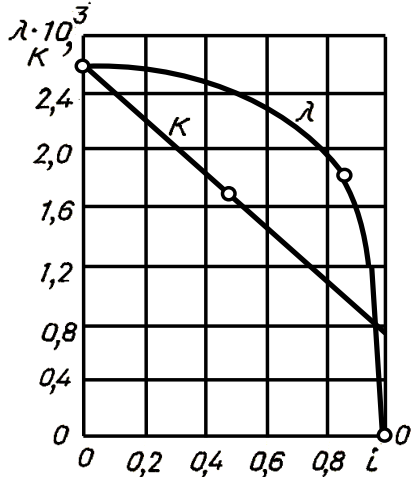

Рис. 2. Безрозмірні характеристики гідротрансформатора Г3-340-36

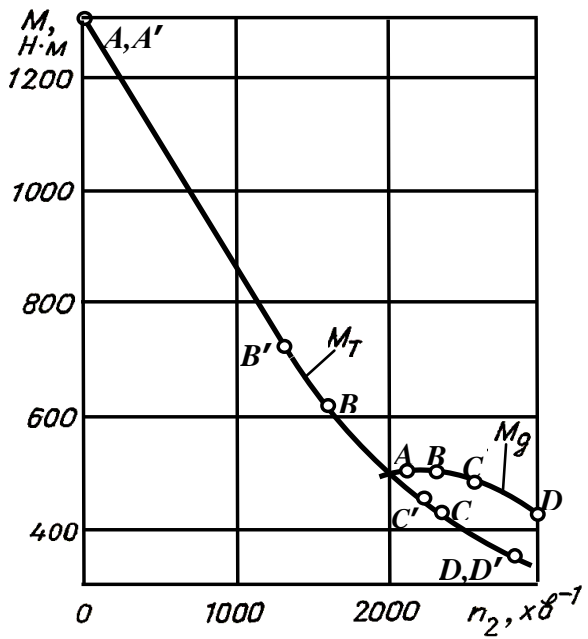

Рис. 3. Вихідна характеристика гідротрансформатора при спільній роботі

Наступні розрахунки проведемо двома способами.

Існуючий спосіб. Для побудови навантажувальних характеристик призначаємо будь-які значення $i$, наприклад, $0 ; 0,7 ; 0,9 ; 0,96.3$ рис. 2 визначаємо, що для цих значень $i$ величина $\lambda \cdot 10^{3}$ дорівнює 2,$59 ; 2,15$; 1,65 i 1,11 . За формулою (1) вираховуємо момент насоса. Частоти обертання вала насоса прийняти такими, щоби хоча б одне значення $M_{\mathrm{H}}$ було більше

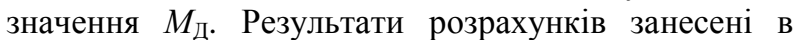
табл. 1. За даними табл. 1 на рис. 1 будуємо навантажувальні характеристики і визначаємо точки $A, B, C, D$ спільної роботи двигуна 3 гідротрансформатором. Для розрахунку параметрів характеристики виходу використовуємо дані $M_{\mathrm{H}}, n_{1}$, $i, K 3$ рис. 1 і 2 . Результати розрахунків наведені в табл. 2.

На рис. 3 показані характеристика виходу $M_{T}=f\left(n_{2}\right)$, тобто лінія $A B C D$, яка побудована за даними табл. 2, а також для порівняння швидкісна характеристика двигуна $M_{\text {д. }}$.

Запропонований спосіб. Визначати навантажувальні характеристики, тобто розраховувати табл. 1 і наносити лінії $M_{H}$ на рис. 1, не потрібно. На швидкісну характеристику двигуна наносимо точки $A^{\prime}, B^{\prime}, C^{\prime}, D^{\prime}$.

Для розрахунку характеристики виходу підготуємо табл. 3 , в яку записуємо координати точок $A^{\prime}$, $B^{\prime}, C^{\prime}, D^{\prime}$ вже під назвами $M_{\mathrm{H}}$ i $n_{l}$.

Далі для кожної з точок розраховуємо значення коефіцієнтів $\lambda$ виходячи з формули (2)

$$
\lambda=\frac{900 \cdot M_{H}}{\rho \cdot 3,14^{2} \cdot n_{1}^{2} \cdot D^{5}}=F \frac{M_{H}}{n_{1}^{2}},
$$

Таблиия 1

Навантажувальні характеристики гідротрансформатора

\begin{tabular}{|c|c|c|c|c|c|c|c|c|c|}
\hline \multirow{2}{*}{ Точка } & \multirow{2}{*}{$i$} & \multirow{2}{*}{$\lambda \cdot 10^{3}$} & \multicolumn{7}{|c|}{$M_{H}, \mathrm{H} \cdot \mathrm{M}$ при $n_{1}, \mathrm{xв}^{-1}$} \\
\cline { 4 - 11 } & & & 2000 & 2100 & 2200 & 2400 & 2500 & 2700 & 3000 \\
\hline$A$ & 0 & 2,59 & 470 & 525 & & & & & \\
\hline$B$ & 0,7 & 2,15 & & & 435 & 509 & & & \\
\hline$C$ & 0,9 & 1,65 & & & & & 432 & 503 & \\
\hline$D$ & 0,96 & 1,11 & & & & & & & 420 \\
\hline
\end{tabular}

Таблиия 2

Вихідна характеристика гідротрансформатора за існуючим способом

\begin{tabular}{|c|c|c|c|c|c|c|}
\hline Точка & $i$ & $K$ & $\begin{array}{c}M_{H}, \\
\mathrm{H} \cdot \mathrm{M}\end{array}$ & $\begin{array}{c}n_{1}, \mathrm{xB}^{-} \\
1\end{array}$ & $\begin{array}{c}M_{T}, \\
\mathrm{H} \cdot \mathrm{M}\end{array}$ & $\begin{array}{c}n_{2}, \\
\mathrm{xB}^{-1}\end{array}$ \\
\hline$A$ & 0 & 2,6 & 500 & 2060 & 1300 & 0 \\
\hline$B$ & 0,7 & 1,25 & 490 & 2350 & 740 & 1350 \\
\hline$C$ & 0,9 & 0,9 & 470 & 2620 & 456 & 2246 \\
\hline$D$ & 0,96 & 0,83 & 420 & 3000 & 350 & 2880 \\
\hline
\end{tabular}

Таблиия 3

Вихідна характеристика гідротрансформатора за запропонованим способом

\begin{tabular}{|c|c|c|c|c|c|c|c|}
\hline Точка & $\begin{array}{c}M_{H}, \\
\mathrm{H} \cdot \mathrm{M}\end{array}$ & $\begin{array}{c}n_{1}, \\
\mathrm{xB}^{-1}\end{array}$ & $\lambda \cdot 10^{3}$ & $i$ & $K$ & $\begin{array}{c}M_{T}, \\
\mathrm{H} \cdot \mathrm{M}\end{array}$ & $\begin{array}{c}n_{2}, \\
\mathrm{xB}^{-1}\end{array}$ \\
\hline$A^{\prime}$ & 500 & 2060 & 2,59 & 0 & 2,6 & 1300 & 0 \\
\hline$B^{\prime}$ & 495 & 2250 & 2,3 & 0,6 & 1,5 & 740 & 1350 \\
\hline$C^{\prime}$ & 475 & 2580 & 1,7 & 0,87 & 0,96 & 456 & 2246 \\
\hline$D^{\prime}$ & 420 & 3000 & 1,11 & 0,96 & 0,83 & 350 & 2880 \\
\hline
\end{tabular}


де $M_{\mathrm{H}}$ i $n_{l}$ - координати визначеної точки, $D$ - діаметр вибраного гідротрансформатора, $F$ - величина, яка $є$ постійною для цього гідротрансформатора

$$
F=\frac{900}{\rho \cdot 3,14^{2} \cdot D^{5}}=\frac{900}{840 \cdot 3,14^{2} \cdot 0,34^{5}}=23,9 \text {. }
$$

Для точки $A^{\prime}$ параметри $M_{\mathrm{H}}, n_{1}, \lambda, i$ та $K$ ті ж cамі, що і при визначенні діаметра $D$ гідротрансформатора.

$$
\begin{aligned}
& \text { Для точок } B^{\prime}, C^{\prime}, D^{\prime} \\
& \lambda_{B}=23,9 \frac{495}{2250^{2}}=0,0023=2,3 \cdot 10^{-3} ; \\
& \lambda_{C}=23,9 \frac{475}{2580^{2}}=0,0017=1,7 \cdot 10^{-3} ; \\
& \lambda_{D}=23,9 \frac{420}{3000^{2}}=0,00111=1,11 \cdot 10^{-3} .
\end{aligned}
$$

За визначеними значеннями коефіцієнтів $\lambda$ з рис. 2 знаходимо параметри $i$ та $K$. За формулами $M_{T}=K \cdot M_{H}, n_{2}=i \cdot n_{1}$ вираховуємо координати точок вихідної характеристики, які наносимо на графік (рис. 3). З'єднавши ці точки, отримуємо вихідну характеристику $M_{T}=f\left(n_{2}\right)$.

Як видно, точки $A, B, C, D$ і $A^{\prime}, B^{\prime}, C^{\prime}, D^{\prime}$ знаходяться на одній лінії $M_{T}$. Отже, розрахунок за двома способами дає однакову вихідну характеристику гідротрансформатора. Тому для визначення вихідної характеристики гідротрансформатора доцільно використовувати запропонований спосіб, основною перевагою якого $€$ спрощення розрахунків i зменшення можливості виникнення помилок.

Виконання такої розрахунково-графічної роботи корисно тим, що курсант особисто пересвідчується в ефективності гідротрансформаторів.

Так, в даному прикладі двигун працює в інтервалі $A D\left(n=2060 \ldots 3000 \mathrm{xB}^{-1} ; M=500 \ldots 420 \mathrm{H} \cdot \mathrm{м}\right)$, а вихідний вал гідротрансформатора - в набагато більшому інтервалі $A^{\prime} D^{\prime}\left(n=0 . .2800 \mathrm{xB}^{-1} ; M=\right.$ 1300 ...350 H·м).

3 використанням описаного способу виконані розрахунки та побудовані вихідні характеристики для ГМП “Львів-3” (рис. 4). Стрілками вниз відмічені частоти обертання вихідного вала при прямих перемиканнях, тобто під час розгону автобуса, стрілками вверх - при зворотних перемиканнях (при гальмуванні).

ГМП “Львів-3" виготовляється на Львівському заводі гідромеханічних передач за документацією, розробленою ВАТ „Український інститут автобусотролейбусобудування", і встановлюється на автобусах ЛиАЗ-5256 [5].

Передача складається 3 комплексного двореакторного гідротрансформатора ЛГ4-370-49 (литий гідротрансформатор з активним діаметром 370 мм і лопатевою системою 49 моделі), сповільнювача, олійної системи і механіч ного триступеневого редуктора, гідродинамічного електрогідравлічної

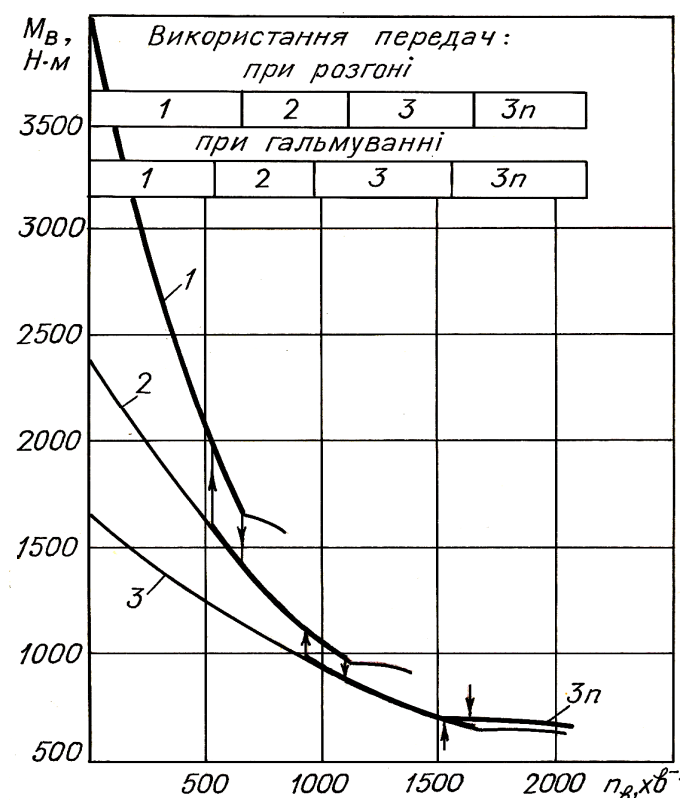

Рис. 4. Вихідні характеристики при спільній роботі ГМП ,Львів-3” з двигуном КамАЗ 7408: Передачі: 1 - перша; 2 - друга; 3 - третя; $3 n$ - третя пряма і характеристика двигуна

системи керування. Максимальний коефіцієнт трансформації моменту гідротрансформатора - 2,4, передавальне число редуктора на першій передачі 2,43, найбільше передавальне число ГМП - 5,83.

\section{Висновки}

Для визначення вихідної характеристики гідротрансформатора доцільно використовувати запропонований спосіб, перевагою якого $\epsilon$ спрощення розрахунків і зменшення можливості виникнення помилок.

\section{Список літератури}

1. Армійські автомобілі. Основи руху, будова, характеристики / [3а ред. Б.Д. Білоуса] - Львів: Видавництво НУЛП, 2007.- 536 c.

2. ГОСТ 20228 - 74. Гидротрансформаторы автомобилей, автобусов и тракторов. Основные параметры. - М.: Издательство стандартов, 1985. - 7 c.

3. Лаптев Ю.Н. Автотракторные гидротрансформаторы. - М.: Машиностроение, 1973. - 280 c.

4. Проектирование трансмиссий автомобилей. Справочник / [Под ред. А.И. Гришкевича]. - М.: Машиностроение, 1984. - 272 c.

5. Трехступенчатая гидромеханическая передача автобуса / Ю.А. Пьтккин, О.И. Гируикий, М.Н. Дзядык. М.: Транспорт, 1980. -152 c.

6. Трусов С.М. Автомобильные гидротрансформаторы. - М.: Машиностроение, 1977. - 271 с.

Рецензент: д.т.н., проф. Л.В. Крайник, голова правління ВАТ “Український інститут автобусотролейбусобудування”, м. Львів. 


\title{
СПОСОБ ПОСТРОЕНИЯ ВЫХОДНОЙ ХАРАКТЕРИСТИКИ ГИДРОТРАНСФОРМАТОРА ПРИ СОВМЕСТНОЙ РАБОТЕ С ДВИГАТЕЛЕМ
}

\author{
В.И. Мандрус
}

Предложен упрощенный способ построения выходной характеристики гидротрансформатора при совместной работе с двигателем, который по сравнению с существующим уменьшает количество расчетов и, следовательно, возможность ошибок, возникающих при проектировании и выполнении расчетно-графических заданий студентами, курсантами, слушателями.

Ключевые слова: гидротрансформатор, характеристики гидротрансформатора, гидромеханическая передача.

\section{THE METHOD OF CONSTRUCTING THE OUTPUT CHARACTERISTIC OF THE HYDRAULIC TRANSFOR- MER IN SOINT WORK WITH THE ENGINE}

\author{
V. Mandrus
}

A simplified method for constructing the output characteristic of the hydraulic transformer in soint work the engine is suggested, which in comparison with the existing method reduces the number of calculations and, therefore, the possibility of errors in the design and implementation of computational and graphic tasks for students and cadets.

Key words: hydraulic transformer, the characteristics of the hydraulic transformer, hydraulic mechanical transmission.

\section{УДК621.396.97}

\author{
Е.К. Поздняков ${ }^{1}$, В.Н. Ткаченко ${ }^{2}$, В.В. Коротков ${ }^{1}$ \\ ${ }^{1}$ ПАО «СКБ РТУ», Донеияк \\ ${ }^{2}$ Институт прикладной механики и математики, Донеияк
}

\section{ПОВЫШЕНИЕ ТОЧНОСТИ ОПРЕДЕЛЕНИЯ ПЕРИОДА ВРАЩЕНИЯ АНТЕННЫХ СИСТЕМ РЛС ПАССИВНЫМИ МНОГОПОЗИЦИОННЫМИ КОМПЛЕКСАМИ ПРИ ПОМОЩИ АВТОКОРРЕЛЯЦИОННОЙ ФУНКЦИИ}

В данной статье выполнено сравнение метрологических характеристик различных методов определения периода вращения антенных систем РЛС. Проанализированы характерные искажения сигнала, возникающие при его прохождении через тропосферу. Обоснована иелесообразность использования автокорреляциионной функции с предварительной параметрической фильтрацией сигнала для определения периода вращчения антенных систем РЛС. Выработаны рекомендации по применению предлагаемого метода в пассивных многопозиционных комплексах контроля радиоэлектронной обстановки.

Ключевые слова: пассивный многопозиционный комплекс, автокорреляционная функция, импульсный сигнал, период, пачка импульсов, фильтрациия.

\section{Постановка проблемы}

В пассивных многопозиционных комплексах (ПМК) контроля радиоэлектронной обстановки при определении координат целей широко применяют методы, основанные на использовании временных параметров излучаемой аппаратуры. Период вращения антенной системы (ПВ АC) радиолокационной станции (РЛС) является важным параметром и, в общем случае, соответствует периоду сигнала (ПС). Точность вычисления координат целей существенно зависит от точности определения ПВ АС.
Задача определения ПВ АC значительно усложняется в условиях дальней тропосферной разведки (ДТР). В процессе распространения в тропосфере искажениям подвергаются следующие параметры сигнала: амплитуда импульсов, форма импульсов (передний фронт, задний фронт, вершина), длительность импульсов (период повторения импульсов, форма огибающей серии (пачки) импульсов). Наибольшим искажениям подвергаются форма огибающей серии (пачки) импульсов, задний фронт импульсов. Таким образом, существует необходимость разработки 